\title{
Original Orticle
}

\section{Socio-cultural determinants and impact of HIV infection in the Sudan}

\author{
W. M. Abdelmagid Ibrahim, Y. A. A. Mohamed, M. Osman, O. Nemery,
} S. Aly Humaida, M. Homeida*

\begin{abstract}
Background: Sudan, among the Subsaharan African countries has a low prevalence of HIV infection particularly in the North of the predominantly Muslim population. The peace agreement (2005) which stopped the civil war in the South opened the boarders with the HIV-high prevalence countries of Central and West Africa.

This is expected to increase the transmission of HIV in the whole of Sudan.

Methods and results: The present study interviewed 635 HIV positive individuals reporting for testing in three voluntary counseling and treatment (VCT) centres in Khartoum. Socio-cultural determinants of the infection showed that the young adults less than 50 years constitute $66.1 \%$ of all infected, with $60 \%$ males, $40 \%$ females and majority $64.9 \%$ are either illiterate or had minimum level of education. $61 \%$ of them were Muslims and $39 \%$ were Christians or non believers, $50.1 \%$ were married. The quality of life changed in $89 \%$ of individuals.

Conclusion: It is concluded that the infection with HIV in Sudan may increase and health education messages need to be tailored according to the sociocultural determinants of the infection in a multicultural, multi-religious country like the Sudan. Muslims will not be protected against HIV infection unless they adhere to the code of Islam.
\end{abstract}

Keywords: human immuno-deficiency virus, Muslims, Subsaharan

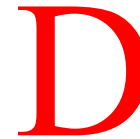
espite the international effort to control the spread of human immunodeficiency virus (HIV) in Subsaharan Africa, the incidence of the infection is increasing, with a population of 770 million; 30 million are estimated to be infected with HIV. In developing countries, French et $\mathrm{al}^{1}$ felt that with 4.9 million new HIV infections in 2005, the transmission is not being prevented.

The prevalence of HIV infection in predominantly Muslim North African countries and other Muslim countries has been low ${ }^{2,3}$. According to the United Nation statistics ${ }^{4}$, North Africa and the Middle East account for less than $1 \%$ of the total number of people infected worldwide with HIV.

\footnotetext{
*Universityo f Medical Sciences and Technology, Khartoum, Sudan Correspondence to: M. Homeida. E-mail: homeidam@umst-edu.org
}

Sudan, though predominantly a Muslim country stands to be different from other North African countries in relation to the spread of HIV.

The Southern provinces, which boarder the HIV belt of Central and East Africa, have different socio-cultural beliefs from those in the North of the country.

The civil war in Southern Sudan (1983-2005) have resulted in isolation of the population in these areas and limited the population movement from the South to the other areas. The recently signed comprehensive peace agreement between the government of Sudan and the Rebel movement (2005) has opened the frontiers of Southern Sudan not only to the North, but to all neighbouring African countries with return of Sudanese refugees and other nationals. Ugandans and Kenyans constitute a high percentage of workers in the 
new-peaceful South, especially in hotels, schools and sex trade.

Generally, there is paucity of published information on the prevalence of HIV infection in the Sudan, its mode of transmission and the sociocultural beliefs regarding HIV infection or the disease associated with the AIDS infection. According to the recently released UNAIDS/WHO 2008 report(5) on the global epidemic, the estimated 2007, of HIV prevalence in adults (15-49) in the Sudan is $1.4 \%$. However, published prevalence studies give variable figures depending on the area studied, and the group of individuals who accepted to be tested. Kaiser R. and colleagues $^{5}$ reported the prevalence of HIV infection in post-conflict Southern Sudan as $0.4 \%$ in Rumbek to $4.4 \%$ in Yei towns among the 15-49 years, and in pregnant women between 0.8 and $3.0 \%$ respectively.

After the peace agreement, targeted prevention programmes are urgently needed to prevent the likely increase in infection among the population of the country.

The disease and the infection of HIV stigmatize those known to be HIV/AIDS positive. In a conserved community, like Sudan, it is likely that many individuals may not come forward for testing or receive treatment. It is essential, before designing a prevention programme to determine the social and behavioural characteristics of those infected. The expansion of voluntary counselling centres in many hospitals in Khartoum encouraged individuals to be tested and determine their HIV infection status.

The present study was done in Khartoum State, which accommodates a cosmopolitan population, and this represents all the States in the country. The main objective of the study is to determine who are likely to contract the infection and the impact of the infection on those who harbour the virus.

\section{Methods}

The study was carried out in Khartoum State VCT centre which receives most of the patients from other states in the Sudan for confirmation of suspected HIV infections or patients to be treated for HIV/AIDs.

Three hospitals with facilities for voluntary counseling and antiretroviral therapy are selected, these are The Academy Charity Hospital, Omdurman Teaching Hospital and Bashair Hospital. These three hospitals receive their patients from a wide sector of the population. As treatment is provided free of charge in these centres, it is expected that the majority of infected individuals attend the HIV clinics in these hospitals.

All individuals who tested positive by two serological tests in the centres and confirmed by western blot in the National Central Laboratory in Khartoum are included in the study. Confirmed consent after explaining the nature of the study was obtained from the individuals. The data were collected over six months period (2007-2008).

Identities of the individuals were only known to the director of the centres and the investigators. The identities of the individuals were concealed when data were analysed.

Designed and pretested structured questionnaires were used to collect data on sociodemographic data, sexual behaviour, risk factors and socio-psychological impact of the disease.

The data were analysed using statistical package of social sciences (SPSS). Significance testing of difference between portions was conducted using the Chi-square where applicable, adjusted by Pearson's or Fisher's exact test, depending on the number of observation with a $\mathrm{P}$ value of $0.05 \%$ or less take as significant.

\section{Results}

All patients reporting to the VCT centres in the three hospitals on two randomly selected day/ week (over six months period) were asked to participate in the study after full explanation of its nature. Out of 660 individuals who were confirmed HIV positive 653 accepted to be interviewed. (98.9\% response rate). 
Table 1 shows the sociodemographic characteristics of the study group. $60 \%$ of the study groups were males. The age frequency clearly shows the dominance of the young and the sexually active. The youngest was 16 years while the eldest was 67 years of age with $66.1 \%$ below 50 years.

The majority of the group (64.9\%) tended to be either completely illiterate or with minimum level of education (primary schooling) $30.6 \%$ were unemployed, with $29.1 \%$ being either professional or individuals with good business. The students constitute $4.3 \%$ of the study population. The army soldiers constituted only $8 \%$.

It was noted that $65 \%$ of the group resided in Khartoum State while $33 \%$ came for treatment from other states and $2 \%$ from the displaced refugee camps. $61 \%$ of the study groups were Muslims and 39\% were Christians. $50 \%$ of the study groups were married.

Although it is not possible to determine with certainty how the HIV infection was contracted, $31.8 \%$ of all infected attribute this to unprotected heterosexual contact. $12 \%$ received blood transfusion which was blamed to be the cause of the infection. About 4\% who are practicing homosexual practice thought that this caused the infection.

$27.1 \%$ of all infected population was originally from the South and $12 \%$ are originally from Eritrea or Ethiopia. The rest of $61 \%$ are from North Sudan.

\section{Social impact}

The quality of life was changed in $89 \%$, this included change of job, sense of rejection by family and friends, with $30 \%$ divorced when the spouse was informed.

40 infected individuals expressed negative attitude by having deliberate unprotected sex with non-infected partners.
Table 1: Socio-demographic characteristics of study group

\begin{tabular}{l|ll} 
Characteristic & Frequency & $\%$ \\
\hline Age & 34 & 5.2 \\
$<20$ & 164 & 25.1 \\
$20-29$ & 234 & 35.8 \\
$30-39$ & 127 & 19.5 \\
$40-49$ & 94 & 14.4 \\
$>50$ & & \\
\hline Gender & 392 & 60 \\
Male & 261 & 40 \\
Female & & \\
\hline Marital status & 327 & 50.1 \\
Married & 189 & 28.9 \\
Single & 137 & 21 \\
Widower /Divorced & & \\
\hline Occupation & 200 & 30.6 \\
Unemployed & 52 & 8 \\
Soldiers & 49 & 7.5 \\
Tea seller & 190 & 29.1 \\
Professionals/Busines & & \\
smen & 70 & 10.7 \\
Truck drivers & 28 & 4.3 \\
Students & 64 & 9.8 \\
Others & & \\
\hline Educational level & 224 & 34.3 \\
Illiterate & 200 & 30.6 \\
Primary school & 157 & 24 \\
High & & \\
school & 72 & 11.1 \\
University &
\end{tabular}

\section{Discussion}

There is an increasing acceptance among the Sudanese to consult VCT centres. The Sudan National AIDS programme have established 163 centres in the whole Sudan with 40 centres in the state of Khartoum and 123 in the rest of the country. In the present study $98.9 \%$ of all HIV positive individuals accepted to be interviewed which indicates increasing awareness about the disease and decrease feeling of stigmatization.

As in many other studies the majority of the affected populations are young, sexually active individuals between 20-49 years.

Religious constraints on sexuality may reduce 
the transmission of HIV and other sexually transmitted diseases, as there is evidence that Muslim countries have low prevalence of $\mathrm{HIV}^{2,3}$. Some authors think that this is due to underreporting due to the high stigma associated with HIV infection in these countries. A survey of published articles containing data on HIV prevalence and religious affiliation showed that six out of seven of such studies indicated a negative relationship between HIV prevalence and being a Muslim ${ }^{5}$. It is clear that the adherence to the code of Islam in sexual relationship is key to protecting persons from the infection. Male circumcision which is a religious practice in these countries may also contribute to this low prevalence ${ }^{6,7}$.

However, in the present study $61 \%$ of the infected are Muslims with the rest being either Christian or have no religious affiliation. This represents the percent of Muslim in the general population. Muslims are equally prone to contract the infection if they don't adhere to the code. Of interest, $4 \%$ of the study group confessed to be practicing male homosexuality, another sexual practice which is highly stigmatized in Muslim countries. It is clear that there is a change in sexual behaviour in the community and any programme of health education to prevent the spread of HIV infection should take these changes in consideration.

Two thirds of the HIV positive individuals in the study are illiterate and had minimal schooling. This, in our view, reflects a bias in the sampling as VCT centres in these hospitals offer free services and are attractive to the low socioeconomic groups. The wellto-do, fear of being known prefer to be tested and treated in private clinics than getting the service free from a public hospital. There is a need to increase the level of education and raise health awareness about HIV in low socio-economic classes of the community. The health education message should be adapted to their level of education and economic ability.
Although $12 \%$ of the study groups are from Eritrea or Ethiopia, it is not clear if these and the infected Southerners contracted the infection in Khartoum or they moved with it from their original homes. With opening up of the frontiers, migration of the disease is a possibility.

Many individuals were not clear about how they contracted the infection. Among those who could indicate the cause, $31 \%$ claim it is due to unprotected heterosexual practices. Condoms are still not being distributed free and are unavailable in many health centres. There is resistance among religious sectors and parliamentarians to the idea of promoting condom use for fear of encouraging extramarital sex.

It was not surprising in a community of North Sudan that the quality of life was changed in $89 \%$ of infected persons which included depression, change of job and profound sense of rejection by their family, with $30 \%$ were divorced when the spouse knew. These results indicated the needs to health educate the public about HIV and that it is a disease like any other infections which require special care in treating it. Individuals should be encouraged not to suppress the information and live with the infection. It is concluded that HIV infection is likely to increase in Sudan particularly North Sudan and that more studies are needed to determine the appropriate health education message to control its spread.

\section{References}

1. French N, Kaleebu P; Pisani E et al. Human immunodeficiency virus (HIV) in developing countries. Annals of Tropical Medicine and Parasitology, 2006,100:433-454.

2. Gray PB. HIV and Islam: is HIV prevalence lower among Muslims? Social Science and Medicine, 2004, 58(9): 1751-6. 
3. Lenton C. Will Egypt escape the AIDS epidemic? The Lancet, 1997, 349:1005.

4. Report on the global HIV/AIDS epidemic. Geneva \& Joint Nations programme on HIV/AIDS, 2002.

5. Kraiser R, Kedamo T, Lane J et al. HIV, syphilis, herpes simplex virus 2, and behavioral surveillance among conflict-affected populations in Yei and Rumbek, Southern Sudan. AIDS,2006,20(6): 942-4.
6. Halperin DT, Bailey RC. Male circumcision and HIV infection: 10 years and counting. Lancet, 1999,534:183-1815.

7. Szabo R, V Short R. How does male circumcision protect against HIV infection? British Medical Journal, 2000, 320:1592-1594. 